\title{
Protective Effect of Hydroalcoholic Extract of Salvia officinalis L. against Acute Liver Toxicity of Acetaminophen in Mice
}

\author{
Foruozandeh H.* PhD, Vosughi Niri M. ${ }^{1}$ PhD, Kalantar M. ${ }^{1}$ PhD, Azadi M. ${ }^{1}$ MSc, Samadani M. ${ }^{1}$ MD
}

*Student Research Committee, Ahvaz Jundishapur University of Medical Sciences, Ahvaz, Iran
1Student Research Committee, Ahvaz Jundishapur University of Medical Sciences, Ahvaz, Iran

\begin{abstract}
Aims: The medical herbs play important roles in the treatment of liver diseases. In the traditional medicine, Salvia officinalis is highly used to heal a wide range of diseases. The aim of this study was to investigate the treatment effects of Saliva officinalis on hepatotoxicity due to acetaminophen.

Materials \& Methods: In the experimental study, 60 albino mice were studied. The rats were divided into 6 groups. The first, second, and third groups were physiological serum, crude extract of Saliva officinalis, and 500mg acetaminophen per $1 \mathrm{Kg}$ consumed as single dose, respectively. The fourth, fifth, and sixth groups received 5-day 125, 250, and 500mg per $1 \mathrm{Kg}$ extract of Saliva officinalis, respectively. Then, they received 500mg acetaminophen one hour after the last administration of extract. Blood sampling was done from the carotids of the rats 24hour later, and the levels of bilirubin and liver enzymes were measured. In addition, their liver tissues were studied. Data was analyzed by SPSS 16 software using one-way ANOVA.

Findings: There were significant increases in the direct and complete bilirubin concentration and liver enzymes due to acetaminophen compared to control group $(\mathrm{p}<0.05)$. There were significant reductions in the direct and complete bilirubin and liver enzymes due to 125,250 , and $500 \mathrm{mg}$ per $1 \mathrm{Kg}$ of the extract of Saliva officinalis compared to control group $(\mathrm{p}<0.05)$. The results were confirmed by the histology studies.

Conclusion: 250 and $500 \mathrm{mg}$ per $1 \mathrm{Kg}$ of Saliva officinalis potentially protect the damages caused by acetaminophen. In addition, they considerably improve the tissue damage and the biochemical indices in the liver damages.
\end{abstract}

\section{Keywords}

Acetaminophen [http://www.ncbi.nlm.nih.gov/mesh/68000082];

Salvia officinalis [http://www.ncbi.nlm.nih.gov/mesh/68027543];

Rats, Wistar [http://www.ncbi.nlm.nih.gov/mesh/68017208];

Hepatotoxicity [Not in MeSH]

* Corresponding Author

Tel: +987152242957

Fax: +987152244000

Address: Blood Transfusion Organization, Ghasr Dasht Street, Larestan, Fars, Iran. Postal Code: 74371-58385

hosainforuozandeh@yahoo.com

Received: September 18, $2015 \quad$ Accepted: May 10, 2016 ePublished: June 30, 2016 
149 حسين فروزنده و همكاران

مقدمه

كبد يكى از اندامهاى حياتى بدن انسان است كه عمل سمزدايى تركيبات خارجى، داروها و غيره را انجام مىدهد. در ائ اين حين إن ممكن است كبد صدمه ببيند و باعث بروز بيمارىهاى كبدى شودارهات.

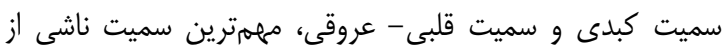

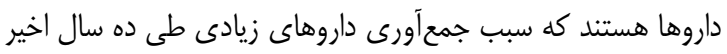

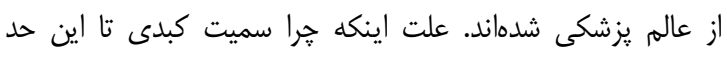
مطرح است به موقعيت و مكان كبد و حجم بالاى تغييرات زيستى

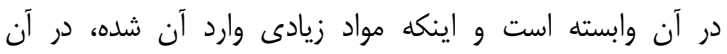
متابوليزه مىشوند كه ممكن است به متابوليتهاى فعال تبديل

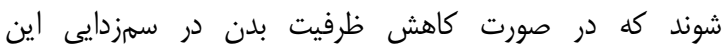

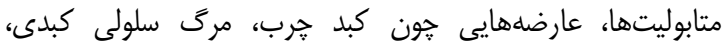
كلستاز مجرى، صدمات مجارى صفراوى، سيروز كبدى، اختلالات عروقى و تومور ايجاد مىشود[2]. آسيب كبدى معمولاً با نكروز سلولى، افزايش يراكسيداسيون بافتى و كاهش سطح سلت كلوتاتيون

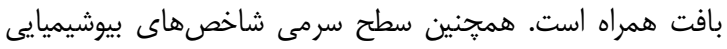
مثل SGPT (سرم كلوتاميك يِيروات ترنسآميناز)، SGOT (سرم كلوتاميك اگزالواستيك ترنسآميناز)، ALP (آلكالينفسفاتاز) و و

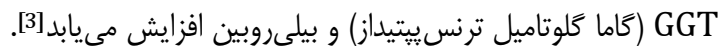

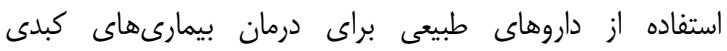

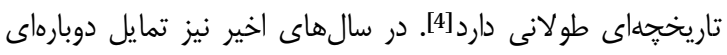

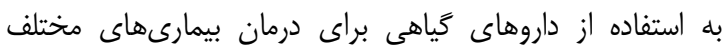

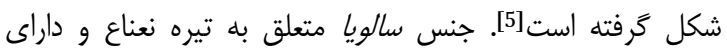

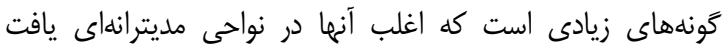

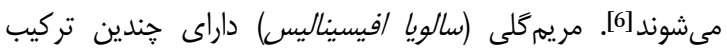
فعال نظير تويون، سينئول، بورنئول، يينن، فلاونوييد، سايونين،

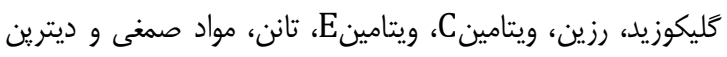

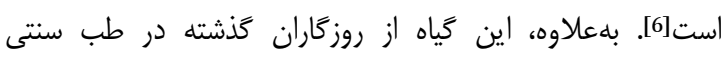

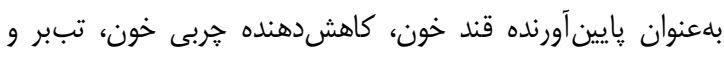

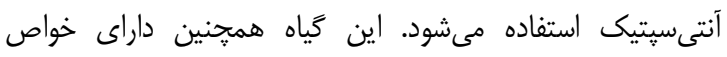

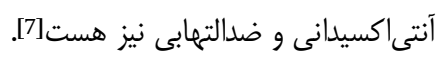
استامينوفن يك داروى مسكن است كه در محدوه دوز درمانى،

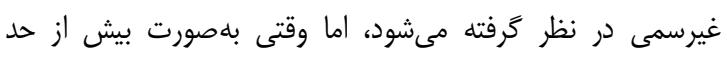
مصرف شود در انسان و گونههاى مختلف حيوانى باعث ايجاد آسيبهاى كبدى مىشود. مطالعات انسانى نشان داده استامينوفن

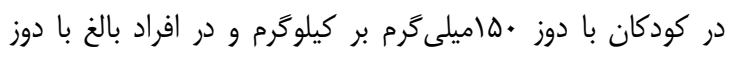

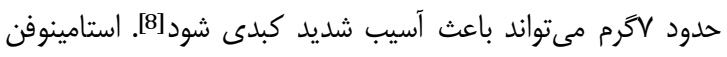

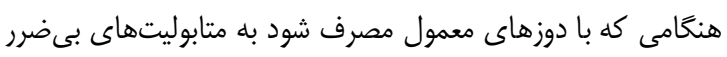

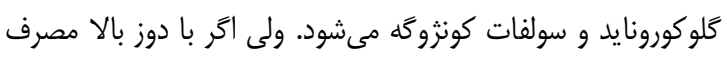
شود، اين مسيرهاى متابوليزمى اشباع مىشود و سيستم وابسته به

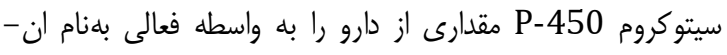
استيل يارابنزوكينون ايمين (NAPAQI) تبديل مى كند. در صورتى به

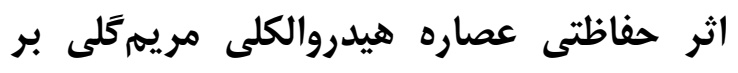
سميت حاد كبدى ناشى از استامينوفن در موشى مريد

سورى سمي

حسين فروزنده

كميته تحقيقات دانشجويى، دانشخاه علوم يزشكى جندى شايور اهواز، اهواز، ايران

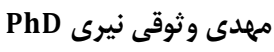

كميته تحقيقات دانشجويى، دانشخاه علوم يزشكى جنى جندى شايور اهواز، اهواز، ايران

مجتبى كلانتر ShD

كميته تحقيقات دانشجويى، دانشگاه علوم يزشكى جندى إندى شايور اهواز، اهواز، ايران

محمد آزادى MSc

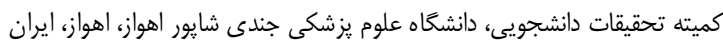

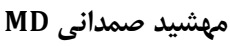

كميته تحقيقات دانشجويى، دانشگاه علوم يزشكى جندى شايور اهواز، اهواز، ايران

جكيده

اهداف: كاربرد گياهان دارويى در درمان بيمارىهاى كبدى از اهميت

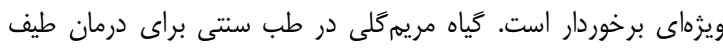

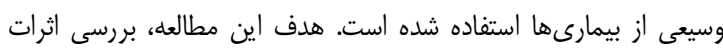
درمانى مريم كلى بر سميت كبدى ناشى از استامينوفن بود. مواد و روشها: در اين مطالعه تجربى •ع سر موش سورى آلبينو به أبه

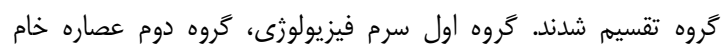

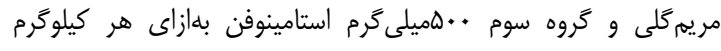

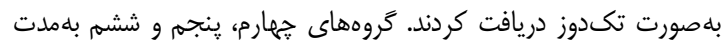

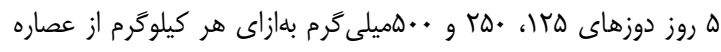

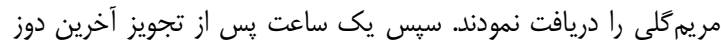

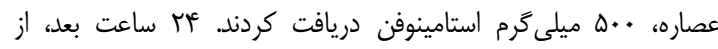

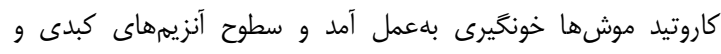

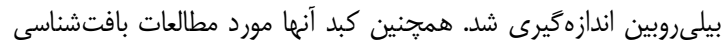

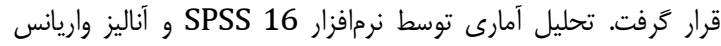
يكىطرفه انجام شد.

يافتهها: تجويز استامينوفن باعث افزايش معنىدار آنزيمهاى كبدى و

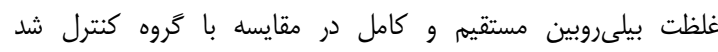

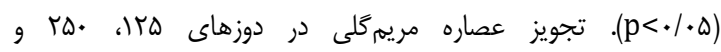

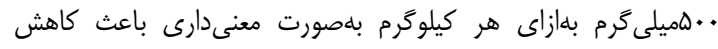

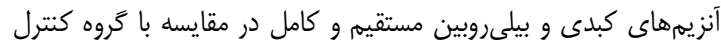

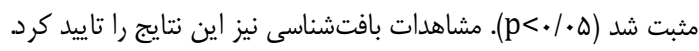

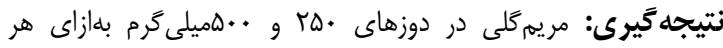

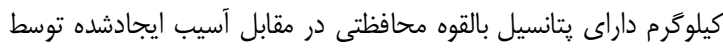

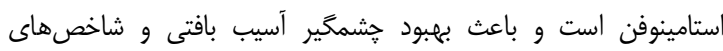
بيوشيميايى در آسيب كبدى مى شود.

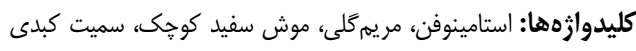

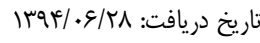

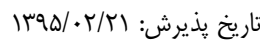
"نويسنده مسئول: hosainforuozandeh@yahoo.com 
اثر حفاظتى عصاره هيدروالكلى مريمَلى بر سميت حاد كبدى ناشى از استامينوفن در موش سورى

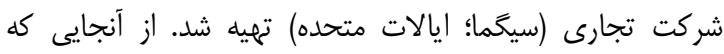

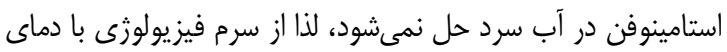

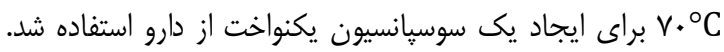

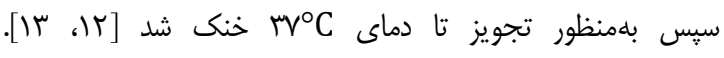

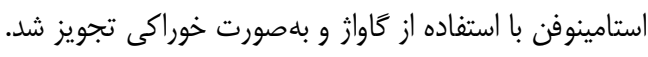
كَروههاى مورد بررسى: حيوانات به و كروه تقسيم شدند كه هر

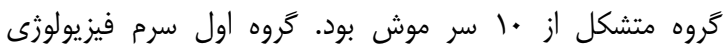

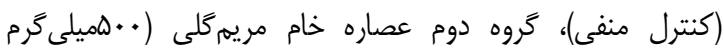

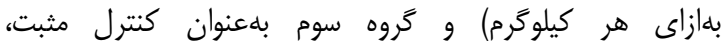

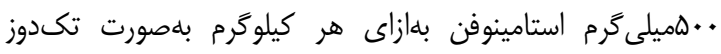

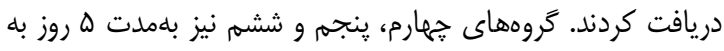

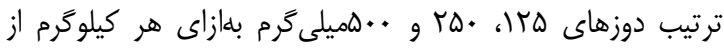

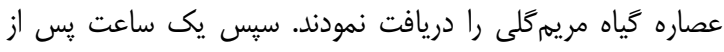

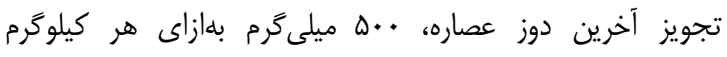

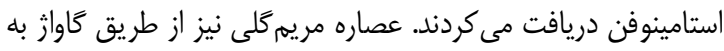
موشها خورانيده شد.

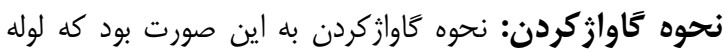
خرطومى كَاواز بهجاى سرسوزن به سرنگ انسولين محتوى عصاره

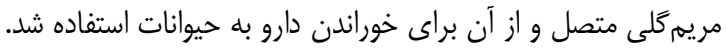

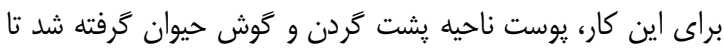
حيوان بلصورت قايم مهار شود. اين امر موجب شد كه دهان حيوان

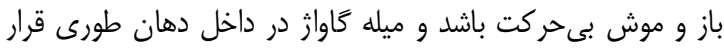

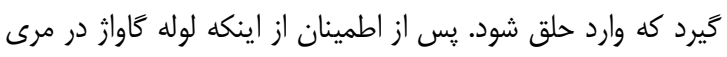

قرار گرفته، عصاره گياه بهصورت خوراكى به به حيوان داده شد.

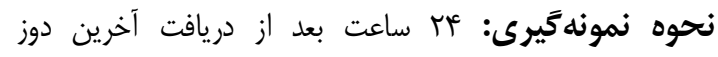
استامينوفن، تمامى گروهها توسط كلروفرم در دسيكاتور بىهوش

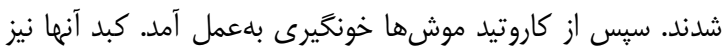

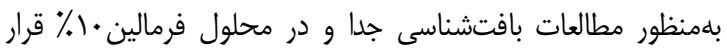

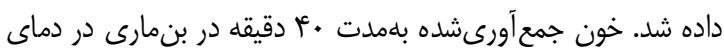

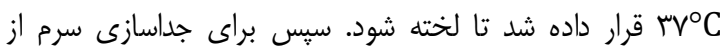

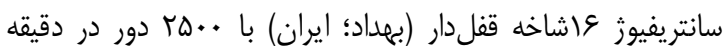
بلممدت • ا دقيقه استفاده شد، تا سرم آن جدا شود.

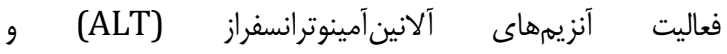

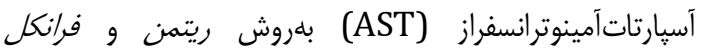

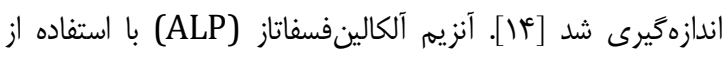

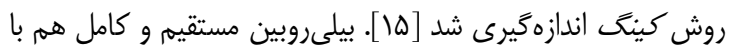

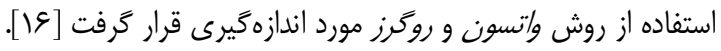

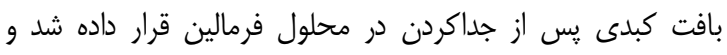

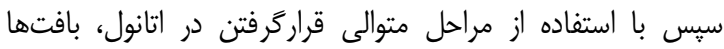
آبزدايى شدند. سيس بافت كبدى آبخيرىشده در يارافين محلول،

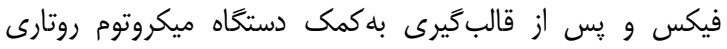
برشهايى بلهقر هميكرون از آن تهيه شد. يس از فيكس كردن
كه ذخاير كلوكاگون كافى باشد با اين ماده كونثوگثه شده و به

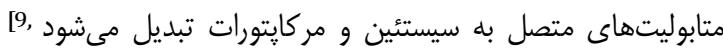

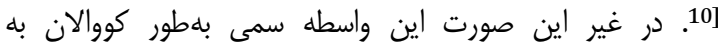
سلولهاى كبدى متصل شده و ايجاد نكروز مركز لوبولى ائى مى كند[11]. با توجه به اينكه دوز بالاى استامينوفن از طريق ايجاد راديكالهاى فعال ايجاد آسيب كبدى مى كند، بنابراين در بسيارى از

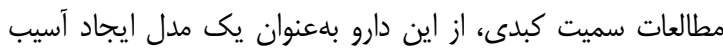
اكسيداتيو كبدى استفاده مىشود.

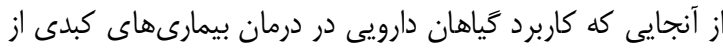

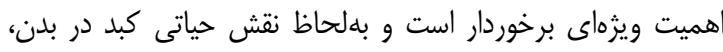
اين مطالعه با هدف بررسى اثرات درمانى مريمكّلى (سالويا

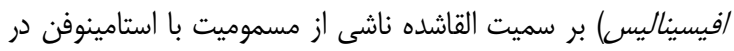

كبد انجام شد.

\section{مواد و روشها} حيوانات آزمايششَاهى: در اين مطالعه تجربى - آزمايشگاهى كه در مركز تحقيقات سمشناسى دانشعاه جندىشايور اهواز در بـار

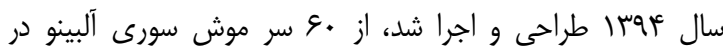

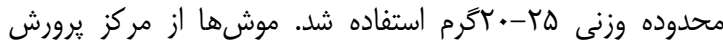

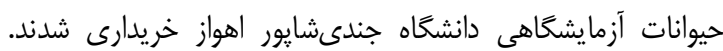

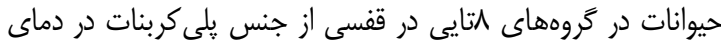
تار نك تاريكى نخمهدارى و توسط غذاى فشرده مخصوص خريدارىشده از شركت خوراى دام و آب لوله كشى شهرى تهرى تغذيه شدند. براى سازگًارى بيشتر با محيط آزمايشگاه و كاهش استرس در حين انجام آزمايش، يك هفته ييش از شروع مطالعه، حيوانات در شرايط مذكور

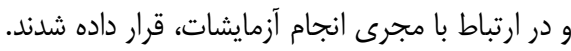

روش تهيه عصاره خشك مريمَّلى: روش تهييه عصاره به اين صورت بود كه ابتدا گل و قسمتهاى هوايى گياه در فصل كلدهى (بهار) از منطقه لارستان در جنوب استان فارس جمع آورى و يس از شناسايى و تشخيص گياه توسط مركز تحقيقات گَياهان

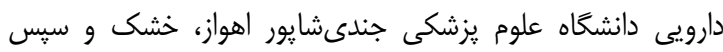
آسياب شد. سيس گياه آسيابشده در مركز تحقيقات سمشناسى

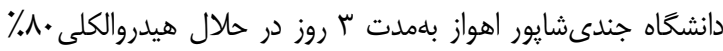

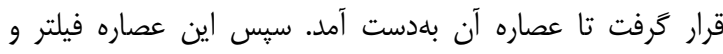
محلول فيلترشده توسط دستخاه سوكسله (هاىدولف ترشياء

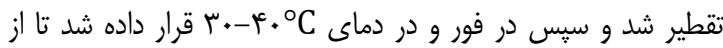
آن عصاره خشك تهيه شود. بازده روش عصارهگيرى عاء

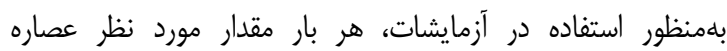
خشك، وزن و در سرم فيزيولوثى حل مى شد. روش تهيه سوسيانسيون استامينوفن: يودر استامينوفن از 
IAN

تجزيه و تحليل آمارى: تجريه و تحليل آمارى با استفاده از

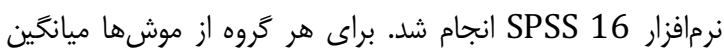

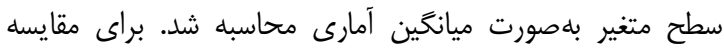

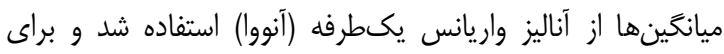

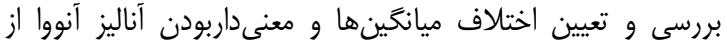

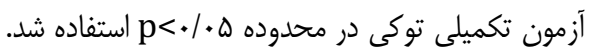

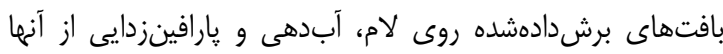

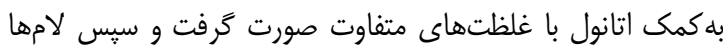

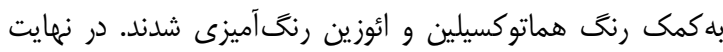

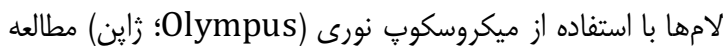

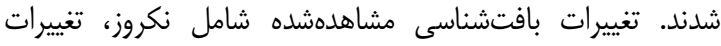
جربى، التهاب و تجمع لنفوسيتها و سلولهاى كويفر بود.

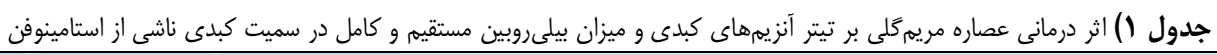

\begin{tabular}{|c|c|c|c|c|c|c|}
\hline | عصاره( +. استامينوفن & 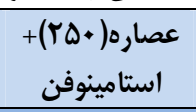 & 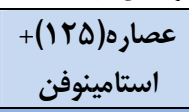 & كنترل مثبت & عصاره & كنترل & متغيرها \\
\hline 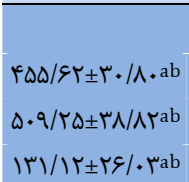 & 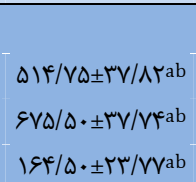 & 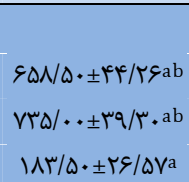 & $\begin{array}{l}V \mid r / T \Delta \pm r N / \cdot r a \\
\Lambda 1 \cdot / r \Delta \pm \Delta \cdot / / \cdot a \\
r \cdot \& / q T+r q / r \Lambda a\end{array}$ & $\begin{array}{l}\Delta \checkmark / \vee \Delta \pm q / \Lambda \cdot b \\
W / r Y \pm r / A Y b \\
\Lambda / V \Lambda \pm r r / \cdot \Delta b\end{array}$ & 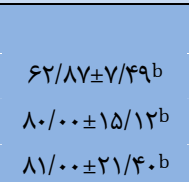 & 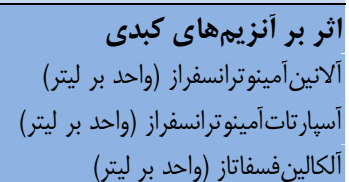 \\
\hline 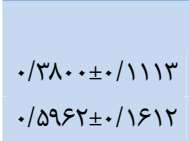 & $\begin{array}{l}. / F \mid r A \pm \cdot / / F V F \\
. / R T V D \pm \cdot / T \cdot q q\end{array}$ & 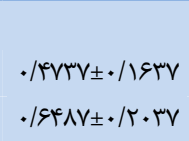 & 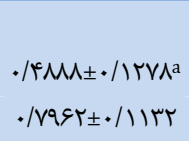 & $\begin{array}{l}\cdot / r q \cdot \cdot \pm \cdot / \cdot q \mu^{\prime b} \\
\cdot / \Delta \cdot / r \pm \cdot / r \mid \Lambda \cdot b\end{array}$ & $\begin{array}{l}\cdot / R \Delta \Delta \cdot \pm \cdot / / Q \mid Q^{b} \\
\cdot / \Delta F M \pm \cdot / / S Q T\end{array}$ & بيلىروبيين مستقييم \\
\hline
\end{tabular}

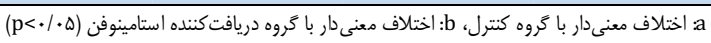

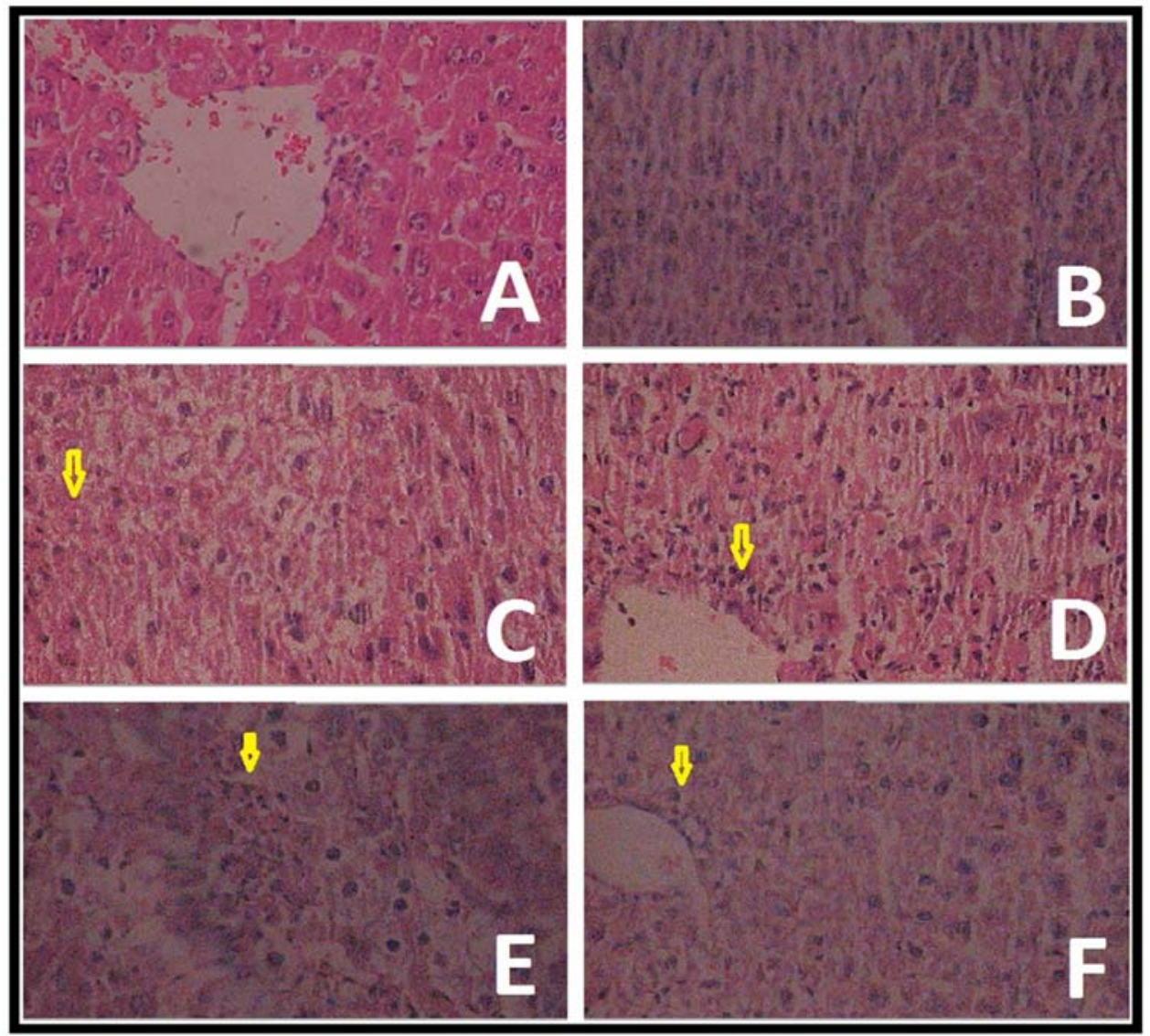

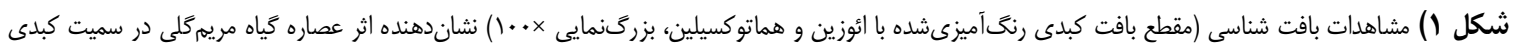

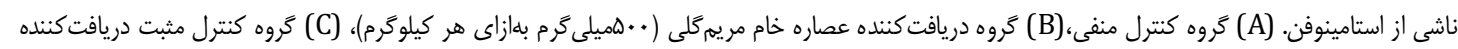

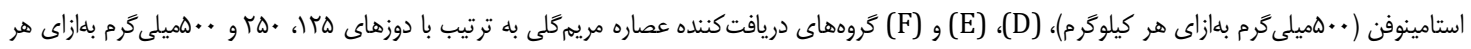

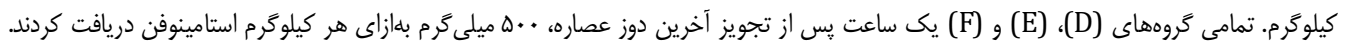




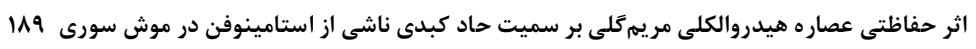

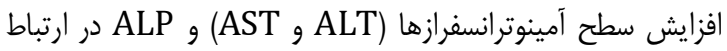

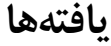

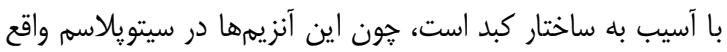

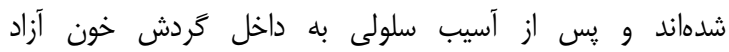
مىشوند [23]. افزايش سطح بيلىروبين در مسموميت با استامينوفن

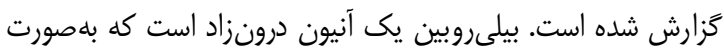

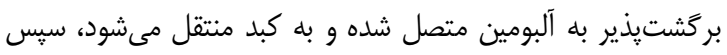

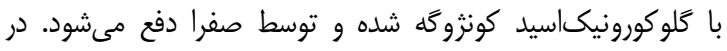
بعضى از بيمارىهاى كبدى ميزان بيلىروبين بالاتر از سطح نرمال

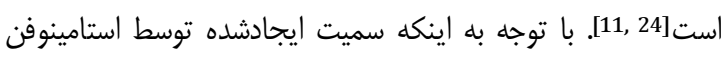

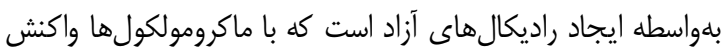

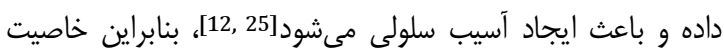

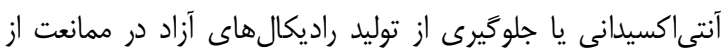

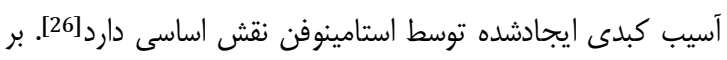

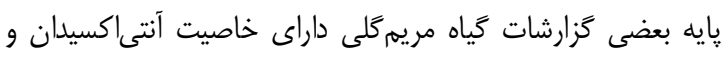

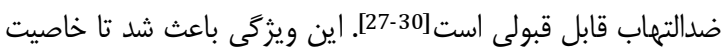
درمانى اين گياه در مقابل سميت كبدى ناشى از استامينوفن مورد بررسى قرار كيرد.

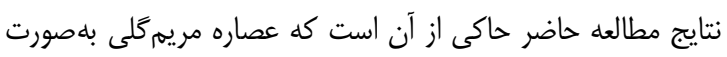

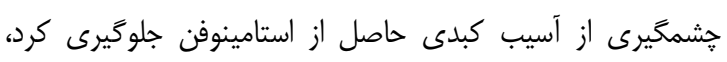

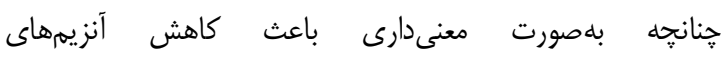

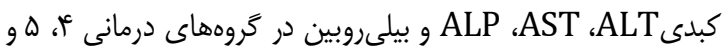

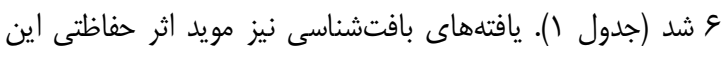

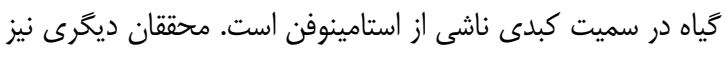

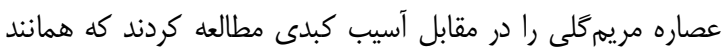

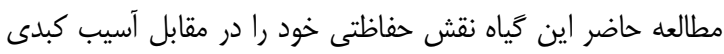
حاصل از مواد شيميايى نشان داد.

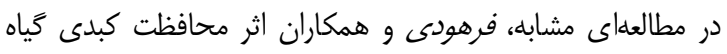

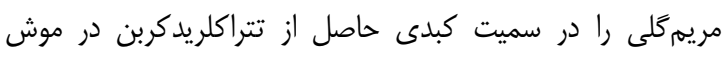

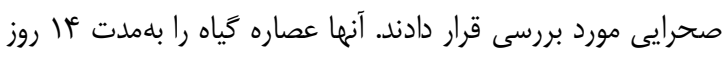

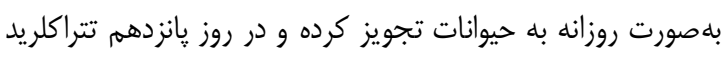

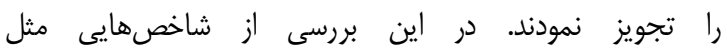

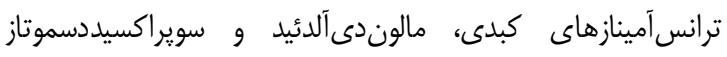

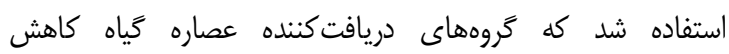

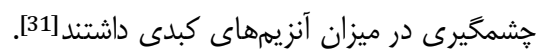

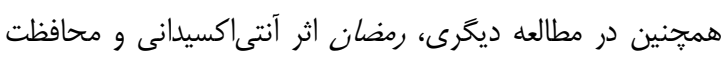

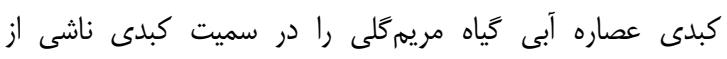

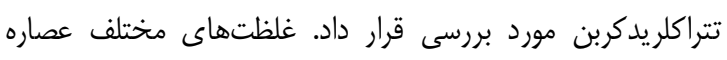

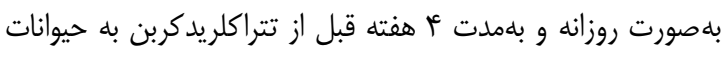

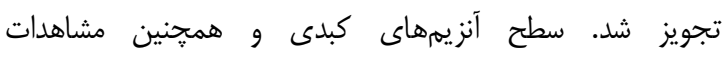

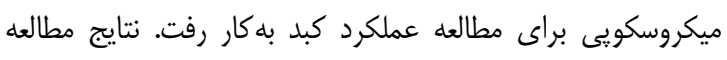

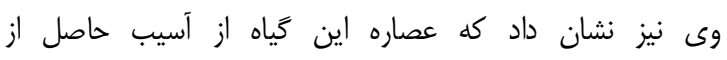

$$
\text { تتراكلر يدكربن جلوَّيرى مى كند [32]. }
$$

يس از تجويز استامينوفن، موشها دهار سميت شديد كبدى شدند

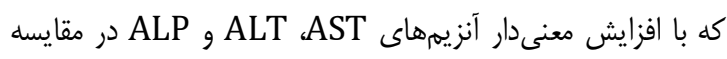

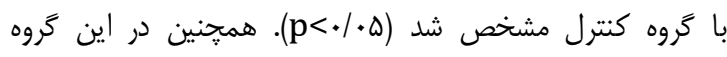

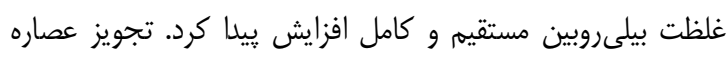

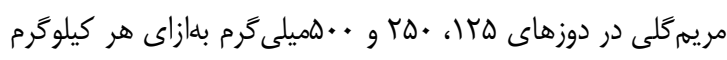

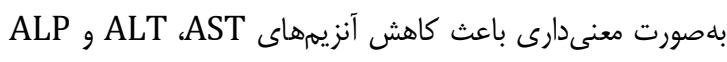

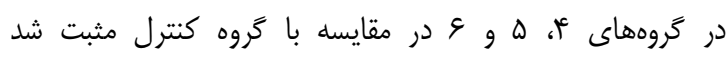

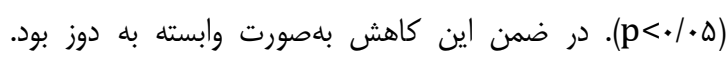

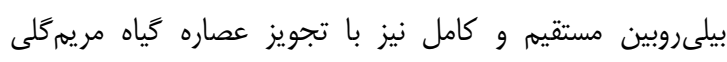

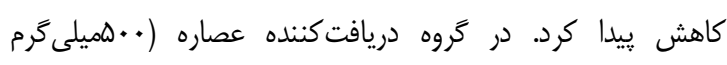

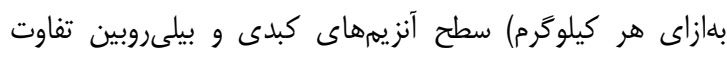

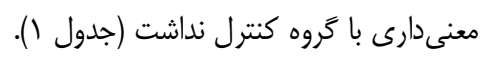
در بررسى هيستوياتولوزى بافت كبد نيز كَروههاى مختل

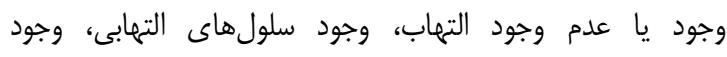

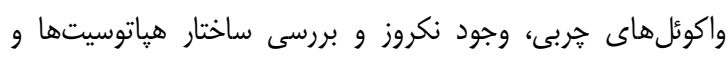

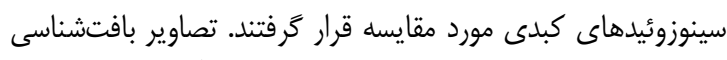

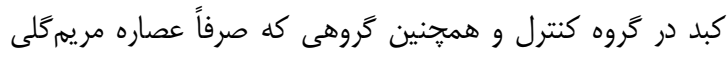

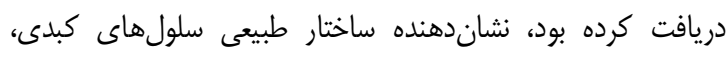

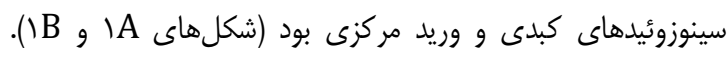

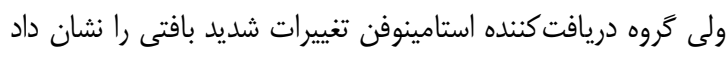

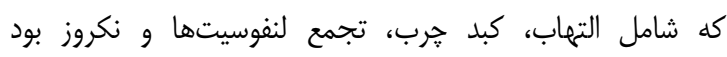

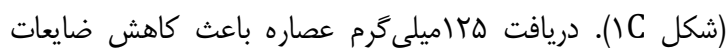

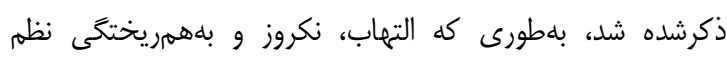

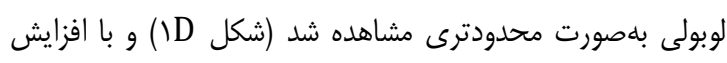

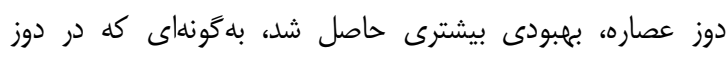

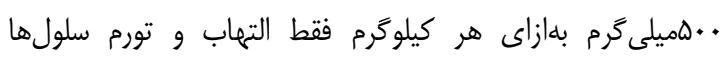

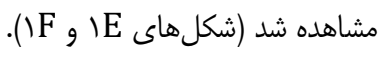

\section{بحث}

كبد يكى از بزركترين اندامهاى بدن است كه داراى عملكرد

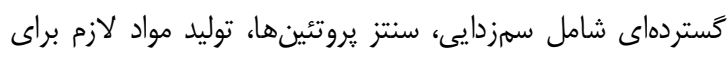

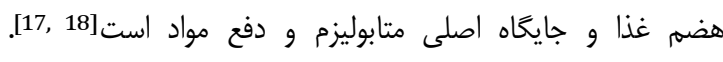

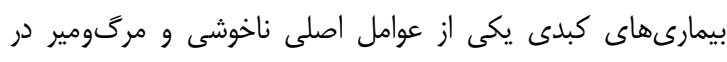

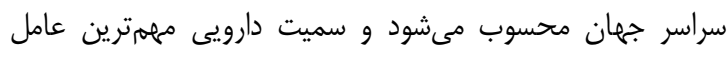
دخيل در اين مورد است] [19,20].

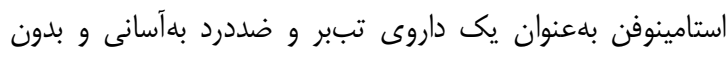

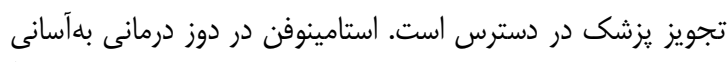
تحمل مىشود، عوارض جانبى و واكنش بـ با ساير داروها معمولاًا

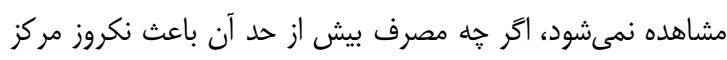

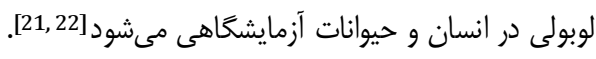


2001;75(2):197-202.

7- Wang M, Li J, Rangarajan M, Shao Y, LaVoie EJ, Huang TC, et al. Antioxidative phenolic compounds from sage (Salvia officinalis). J Agric Food Chem. 1998;46(12):4869-73.

8- Biazar E, Rezayat SM, Montazeri N, Pourshamsian K, Zeinali R, Asefnejad A, et al. The effect of acetaminophen nanoparticles on liver toxicity in a rat model. Int J Nanomedicine. 2010;5:197-201.

9- Corcoran GB, Mitchell JR, Vaishnav YN, Horning EC. Evidence that acetaminophen and $\mathrm{N}$ hydroxyacetaminophen form a common arylating intermediate, N-acetyl-p-benzoquinoneimine. Mol Pharmacol. 1980;18(3):336-42.

10- Park BK, Pirmohamed M, Kitheringham NR. The role of cytochorome p-450 enzymes in hepatic and extrahepatic human drug toxicity. Pharmacy Ther. 1995;68(30):385-424.

11- Yoon E, Babar A, Choudhary M, Kutner M, Pyrsopoulos N. Acetaminophen-induced hepatotoxicity: A comprehensive update. J Clin Transl Hepatol. 2016;4(2):131-6.

12- Sener G, Sehirili AO. Ayanoglu-Dulger G. Protective effect of melatonin, vitamin $\mathrm{E}$ and $\mathrm{N}$-acetylcysteine against acetaminophen toxicity in mice: A comparative study. J Pineal Res. 2003;35(1):61-8.

13- Yapar K, Kart A, Karapehlivan M, Atakisi O, Tunca R, Erginsoy S, et al. Hepatoprotective effect of L-carnitine against acute acetaminophen. Exp Toxicol Pathol. 2007;59(2):121-8.

14- Reitman S, Frankel S. A colorimetric method for the determination of serum levels of glutamic oxaloacetic acid and pyruvic acid transaminases. Am J Clin Pathol. 1957;28(1):56-63.

15- Grohmann K, Roser M, Rolinski B, Kadow I, Mller C, Goerlach-Graw A, et al. Bilirubin measurement for neonates: comparison of 9 frequently used methods. Pediatrics. 2006;117(4):1174-83.

16- Watson D, Rogers JA. A study of six representative methods of plasma bilirubin analysis. J Clin Pathol. 1961;14(3):271-8.

17- Ahsan R, Islam KM, Bulbul IJ, Musaddik A, Haque E. Hepatoprotective activity of methanol extract of some medicinal plants against carbon tetrachloride induced hepatotoxicity in albino rats. Global J Pharmacol. 2009;37(2):302-10.

18- Angelico M, Gridelli B, Strazzabosco M; A.I.S.F. Commission on Liver Transplantation. Practice of adult liver transplantation in Italy: Recommendations of the Italian Association for the Study of the Liver (A.I.S.F.). Dig Liver Dis. 2005;37(7):461-7.

19- Bhawna S, Kumar SU. Hepatoprotective activity of some indigenous plants. Int J Pharm Tech Res. 2009;1(4):1330-4.

20- Forouzandeh H, Azemi ME, Rashidi I, Goudarzi M, Kalantari H. Study of the protective effect of teucrium polium L. extract on acetaminophen- induced hepatotoxicity in mice. Iranian J Pharm Res. 2013;12(1):123-9.

21- Ita SO, Akpanyung EO, Umoh BI, Ben EE, Ukafia SO. Acetaminophen induced hepatic toxicity: Protective role of Ageratum conyzoides. Pak J Nutr. 2009;8(7):928-32. 22- Jollow DJ, Mitchell JR, Potter WZ, Davis DC, Gillette JR, Brodie BB. Acetaminophen-induced hepatic necrosis II; Role of covalent binding in vivo. J Pharmacol Exp Ther. 1973;187(1):195-202.

$$
\begin{aligned}
& \text { از محدوديتهاى اين مطالعه مىتوان به عدان عدمان اندازمكيرى }
\end{aligned}
$$

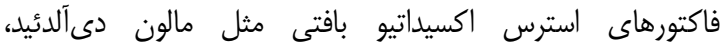

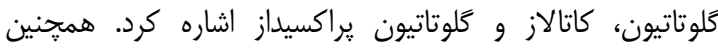

$$
\begin{aligned}
& \text { عصاره تام را مىتوان از نظر تركيبات موثره موجود در آن مورد }
\end{aligned}
$$

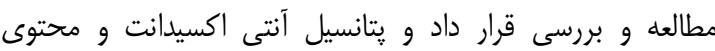

$$
\begin{aligned}
& \text { تركيبات فنلى و فلاونوئيدى آن را اندازهكيرى كرد. }
\end{aligned}
$$

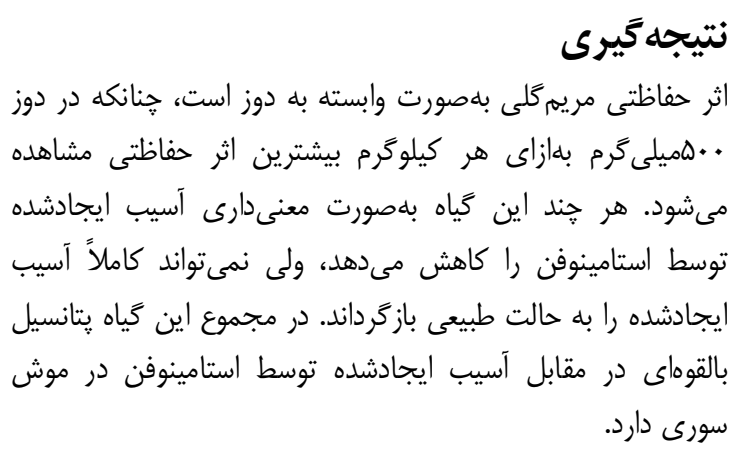$$
\text { تشكر و قدردانى: موردى توسط نويسندكان بيان نشده است. }
$$$$
\text { تاييديه اخلاقى: اين مطالعه براساس دستورالعمل كار با بإن حيوانات }
$$

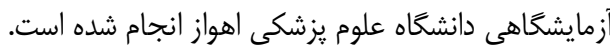

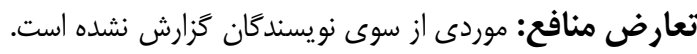$$
\text { منابع مالى: هزينه انجام اين مطالعه توسط كميته تحقيقات }
$$

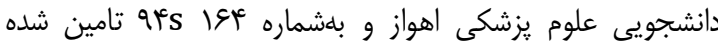$$
\text { است. }
$$

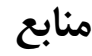

1- Rathi A, Srivastava AK, Shirwaikar A, Singh Rawat AK, Mehrotra S. Hepatoprotective Potential Of Fumaria Indica Pugsley Whole Plant Extracts, Fractions And An Isolated Alkaloid Protopine. Phytomedicine. 2008:15(67):470-7.

2- Grattagliano I, Bonfrate L, Diogo CV, Wang HH, Wang DQ, Portincasa P. Biochemical mechanisms in druginduced liver injury: Certainties and doubts. World J Gastroenterol. 2009;15(39):4865-76.

3- Chaudhari NB, Chittam K, Patil V. Hepatoprotective activity of cassia fistula seeds against paracetamolinduced hepatic injury in rats. Arch Pharm Sci Res. 2009;2(2):218-21.

4- Thyagarajan S, Jayaram S, Gopalakrishnan V, Hari R, Jeyakumar P, Sripathi M. Herbal medicines for liver diseases in India. J Gastroenterol Hepatol. 2002;17 (3):370-6.

5- Ahmed OM, Moneim AA, Yazid IA, Mahmoud AM. antihyperglycemic, antihyperlipidemic and antioxidant effects and the probable mechanisms of action of ruta graveolens infusion and rutin in nicotinamidestreptozotocin-induced diabetic rats. Diabetol. 2010;39(1):15-35.

6- Lu Y, Foo LY. Antioxidant activities of polyphenols from sage (Salvia officinalis). Food Chem

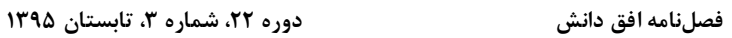


اثر حفاظتى عصاره هيدروالكلى مريمَلى بر سميت حاد كبدى ناشى از استامينوفن در موش سورى 191

vitro. J Med Food. 2009;12(1):77-84.

28- Baricevic D, Bartol T. The biological/pharmacological activity of the Salvia genus. In: Kintzios SE. The Genus Salvia. Boca Raton, Florida: CRC Press; 2000. 143-84.

29- Lalićević S, Djordjević I. Comparison of benzydamine hydrochloride and Salvia officinalis as an adjuvant local treatment to systemic nonsteroidal anti-inflammatory drug in controlling pain after tonsillectomy, adenoidectomy, or both: an open-label, single-blind, randomized clinical trial. Curr therapeu res. Curr Ther Res Clin Exp. 2004;65(4):360-72.

30- Hasani-Ranjbar S, Larijani B, Abdollahi M. A systematic review of the potential herbal sources of future drugs effective in oxidant-related diseases. Inflamm Allergy Drug Targets. 2009;8(1):2-10.

31- Farhoudi M, Ghoratizadeh S, Ghodratizadeh S. Effects of Salvia officinalis extrct on carbon tetrachloride induced hepatotoxicity. Glob Vet. 2011;7(4):353-7.

32- Ramadan RS. Hepatoprotective and antioxidant effects of sage (Salvia officinalis L.) extract against CCl4 intoxicated male rats. Life Sci. 2005;77(3):266-78.
23- Chenoweth MB, Hake CL. The smaller halogenated aliphatic hydrocarbons. Annu Rev Pharmacol. 1962;2(1):363-98.

24- Yamaguchi T, Terakado M, Horio F, Aoki K, Tanaka M, Nakajima H. Role of bilirubin as an antioxidant in an ischemia reperfusion of rat liver and induction of heme oxygenase. Biochem Biophys Res Commun. 1996;223(1):129-35.

25- Zaher H, Buters J, Ward JM, Bruno MK, Lucas AM, Stern ST, et al. Protection against acetaminophen toxicity in CYP1A2 and CYP2E1 double-null mice. Toxicol Appl Pharmacol. 1998;152(1):193-9.

26- Bhoopat L, Srichairatanakool S, Kanjanapothi D, Taesotikul T, Thananchai H, Bhoopat T. Hepatoprotective effects of lychee: A combination of antioxidant and antiapoptotic activities. J Ethnopharmacol. 2011;136(1):5566.

27- Oboh G, Henle T. Antioxidant and inhibitory effects of aqueous extracts of Salvia officinalis leaves on prooxidant-induced lipid peroxidation in brain and liver in 